\title{
Pyrithione Zinc
}

National Cancer Institute

\section{Source}

National Cancer Institute. Pyrithione Zinc. NCI Thesaurus. Code C47698.

A coordination complex of the zinc ion and pyrithione, a derivative of the naturally occurring antibiotic aspergillic acid with antimicrobial, antifung al and anti-seborrheic effects. Although the exact mechanism of action remains to be fully elucidated, pyrithione zinc appears to interfere with the membrane transport of ions and metabolites, ultimately leading to a loss of metabolic control. In addition, this agent causes an influx of copper, leading to a reduction in the activity of iron-sulphur proteins resulting in growth inhibition. 